\title{
Inhaltsübersicht
}

Seite

Vorwort .................................................................................................... V

Autorenverzeichnis ........................................................................................... IX

Literaturverzeichnis ..................................................................................... XIII

\section{A. Gesetzestext}

Gesetz über den Stabilisierungs- und Restrukturierungsrahmen für Unternehmen (Unternehmensstabilisierungs- und -restrukturierungsgesetz - StaRUG) 3

B. Kommentierung des StaRUG

Einleitung

Teil 1

Krisenfrüherkennung und Krisenmanagement

Teil 2

Stabilisierungs- und Restrukturierungsrahmen

$(\mathbb{S} 2-93)$ 97

Kapitel 1

Restrukturierungsplan ( $\left.\int \mathbb{S} 2-28\right)$ 97

Abschnitt 1 Gestaltung von Rechtsverhältnissen $\left(\mathbb{S} \int 2-4\right)$ 97

Abschnitt 2 Anforderungen an den Restruktu161

Abschnitt $3 \quad$ Planabstimmung ( $\left.\int \mathbb{S} 17-28\right)$................... 302

Kapitel 2

Stabilisierungs- und Restrukturierungsinstrumente ( $\left.\iint 29-72\right)$ 433

Abschnitt 1

Allgemeine Bestimmungen

Abschnitt 2 Gerichtliche Planabstimmung 433

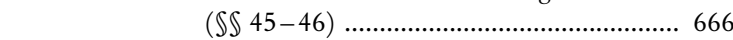

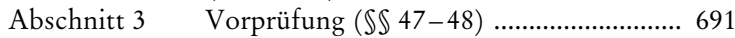

Abschnitt $4 \quad$ Stabilisierung $\left(\mathbb{S} \int 49-59\right)$......................... 698

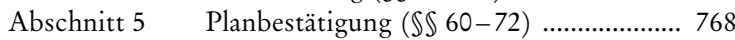

Kapitel 3 Restrukturierungsbeauftragter $\left(\mathbb{S} \int 73-83\right)$........................ 953

Abschnitt 1 Bestellung von Amts wegen

( $\left.\int S 73-76\right)$

Abschnitt 2 Bestellung auf Antrag

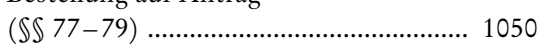

Abschnitt 3 Vergütung $\left(\mathbb{S} \int 80-83\right)$.......................... 1060 


\section{Inhaltsübersicht}

Kapitel 4

Kapitel 5

Kapitel 6

Teil 3

Teil 4
Öffentliche Restrukturierungssachen ( $\left.\iint 84-88\right)$

Anfechtungs- und Haftungsrecht ( $\left.\int \mathbb{S} 89-91\right)$

Arbeitnehmerbeteiligung; Gläubigerbeirat

( $\iint 92-93$ )

Sanierungsmoderation ( $\left.\iint 94-100\right)$

Frühwarnsysteme (SS 101-102)

C. Sanierungssteuerrecht

Steuerliche Fragen der Sanierung i. R. des

Restrukturierungsverfahrens

\section{Anhang}

Richtlinie (EU) 2019/1023 des Europäischen

Parlaments und des Rates vom 20. Juni 2019 über präventive Restrukturierungsrahmen, über Entschuldung und über Tätigkeitsverbote sowie über Maßnahmen zur Steigerung der Effizienz von Restrukturierungs-, Insolvenz- und Entschuldungsver-fahren und zur Änderung der Richtlinie (EU) 2017/1132 (Richtlinie über Restrukturierung und Insolvenz), ABl. (EU) L 172 vom 26.6.2019, S. 18

Stichwortverzeichnis 1399 